\title{
Understanding Diverse Outcomes for Working- Class Learning: Conceptualising Class Consciousness as Knowledge Activity
}

\section{Peter H. Sawchuk*}

\begin{abstract}
This article poses the question: Why is it that work/life teaches some workers resistance and militancy while it seems to teach others despondency, withdrawal or manic careerism? The significance of this question lies in the decline of working-class community. The question is answered through an exploration of ways of conceptualising working-class learning that account for a diversity of outcomes in terms of class consciousness. The article briefly reviews key dimensions of learning theory, and then, by drawing on two empirical illustrations, it argues that the workplace must be conceptualized as an ensemble of work/life spheres. The argument confirms the prospect for a better understanding of the complex nature of work-learning relations with an emphasis on artifact mediation (i.e. the role of tools and ideas) and participatory structures (i.e. activity systems). Here the content and structural location of working-class cultural practices and dispositions (i.e. habitus) within activity systems are deemed central.
\end{abstract}

\section{Introduction}

In this article I explore how capitalist political economy, labour process and labour relations can be integrated into a model of working-class learning to shed light on the question of what it is that work teaches the working-class. Above all, the goal in this article is to begin to open the 'black box' of skill and knowledge development processes in industrial relations and sociology of work

\footnotetext{
* Associate professor, Department of Sociology \& Equity Studies in Education, University of Toronto. E-mail: psawchuk@oise.utoronto.ca
} 
research. Along with others such as Warhurst and Thompson (2006), I argue that a better, more expansive understanding of the 'how' of learning is a stepping stone for more coherent understandings of the relationship between work and working-class life.

Below, I review an integrative model of the field of adult learning theory to establish a firm foundation for analysis in terms of social, as well as cognitive and emotional, dimensions. Building on this review, I make the case for the need for an integrating conceptual 'glue' (i.e. the mediation process) that can 'hold' these disparate dimensions and literatures together for the purposes of meaningful analysis, and then move to a key example of an integrated working-class learning analysis based on a particular socio-cultural approach to learning called Cultural Historical Activity Theory (CHAT). In the latter portion of the article, I apply this theory to empirical illustrations that open a new layer of analysis within a traditional area: the development of class consciousness. I ask, why is it that work/life teaches some workers resistance and militancy while it seems to teach others despondency, withdrawal or enthusiastic self-commodification and manic careerism?

In several ways, the article is a response to that fact that industrial sociology and industrial relations theories of worker cooperation, non-cooperation and resistance, even in their most politicized form of theories of class formation, offer little indication of the process of working-class learning (for a full review see Sawchuk 2006a). Class consciousness is arguably a key learning outcome of work/life, but in these literatures to the degree it is referenced at all it is not understood as a learning accomplishment. Under the type of learning analysis I draw on below, distinct forms of consciousness emerge, based on either the fomenting or resolution of systemic contradictions in relation to working-class cultural dispositions (habitus) and community.

I begin, however, with a brief rationale for looking at working-class learning in the first place. I claim that international patterns of change in workingclass communities have disrupted long-taken-for-granted knowledge production capacities upon which both industry and working-class communities themselves depended.

\section{The Evisceration of Working-Class Community}

The broader significance of my argument in this article lies in the current status or social health of working-class communities under late capitalism. Of course, international generalizations are always tenuous. Nevertheless, a host of sources have recently documented in agonizing detail the forces of dissolution and fragmentation of such communities (e.g. Swift 1995, Forrester 1998, Putnam 2000, Ehrenreich 2002). One recent examination of working-class life in England goes a long way towards capturing the existential and human developmental dimensions of this trend generally:

Describing the nature of working class people in an age of such fragmentation and atomization, especially where so many are so uncertain, is not straightforward... . Since the 1980s, the gradual decline of 
the culture of the working class has been one of the most powerful, telling developments in British society ... The task of trying to capture the voices of working class people, emphasized the gradual effacement of a way of life based around a coherent sense of the dignity of others and of a place in the world. Those around forty have a coherent way of describing their lives and a sense of what has happened to the working class, but as one comes down through the generations, one moves away from the efficacy of any narrative of the social, away from the co-ordinates of class and encounters an arid individualism devoid of personal embedding in something beyond the ego... During a period of mass unemployment, in which work has become more atomized and more precarious, insecurity has become the condition of too many. Elementary solidarities of family, work and place, once consolidated by the culture of the trade union and tertiary education, have been washed away by the corrosive cleansing of laissez-faire economic practice... (Charlesworth 2000:1-5)

Indeed, an article from the October 2006 issue of The Economist begins with a picture of the working-class that Charlesworth speaks of with the words 'Welcome to Hell' spray painted across a brick wall foregrounded by youngsters of the east London neighbourhood of Dagenham looking on. Though this is not the space for a full exploration, under such conditions, so prevalent in advanced industrialized countries around the globe, it is not hard to understand that working-class knowledge production capacity may be a casualty. Certainly stagnation, crisis, destruction, re-settlement, resumed economic growth and so on have been the hallmark of capitalism from the beginning (e.g. Maddison, 1982). However, it becomes increasingly difficult to argue that this current phase of capitalism has not ushered in something unique in terms of the new freedoms felt by capital: to detach itself from social provision, to move, to contract, and to freely trade across the planet. The results are new levels of economic isolation against a backdrop of turbulence and social fragmentation for the diverse, working-class majority.

It would seem then that late capitalism has presented us with a qualitatively new level of difficulty as a society, and amongst the many casualties are the conditions through which workers' traditional knowledge are created within functional working-class communities. Comparatively, and beyond the temptation of nostalgia, the fact is that the capacity for producing rich forms of everyday knowledge were present more abundantly in the great working-class communities of old, associated with the 'golden era' of Fordism (1940-70). Indeed, as we argued in Livingstone and Sawchuk (2004) the 'hidden knowledge' of working-class community, so important for their own social development as well as genuine economic productivity may be one of the least discussed victims of all.

However, an analysis of subordination and knowledge production within this state of evisceration is incomplete without recognition of the points of resistance. The capacities of working-class groups, particularly unionized ones, can and still do stubbornly resist these forces of evisceration (see Foley 1999; Sawchuk 2003; Livingstone and Sawchuk 2004) particularly where there re- 
main vestiges of social stabilisation (e.g. a strong welfare state, strong labour laws, workers' political parties, significant social capital, and so on). At the centre of this claim are instances of the accumulation of scarce discretionary time, the pooling of scarce resources and the collective development of knowledge and skill that recognizes - indeed positively expresses - working-class standpoints. These are some of the important needs that are met by functioning working-class learning networks (Sawchuk, 2003).

\section{Assaying the Dimensions of Learning Theory}

In moving from an assessment of the social conditions to a discussion of knowledge production capacity, we are presented with an enormous number of alternatives pathways for analysis (cf. Fenwick and Farrell, in press; Fenwick, Nesbit and Spencer 2006). In what is today the most comprehensive framework for understanding adult learning theory, Illeris (2002) traced the key foundational components of human development, organizing the field within a unified framework: 'All learning comprises three different dimensions - i.e., ... all learning is, so to speak, stretched out between three poles and accordingly may be looked at and analysed from three different approaches' (p. 18). Irreducibly, human learning always involves all three dimensions at the same time. These dimensions are the cognitive, the emotional, and the social, mapped onto what Illeris calls a 'tension field' of learning. Within this field he locates theories of adult learning according to their central preoccupations and conceptual strengths (see Figure 1).

FIGURE 1: Illeris's Tension Field of Learning Theory (IIleris 2002)

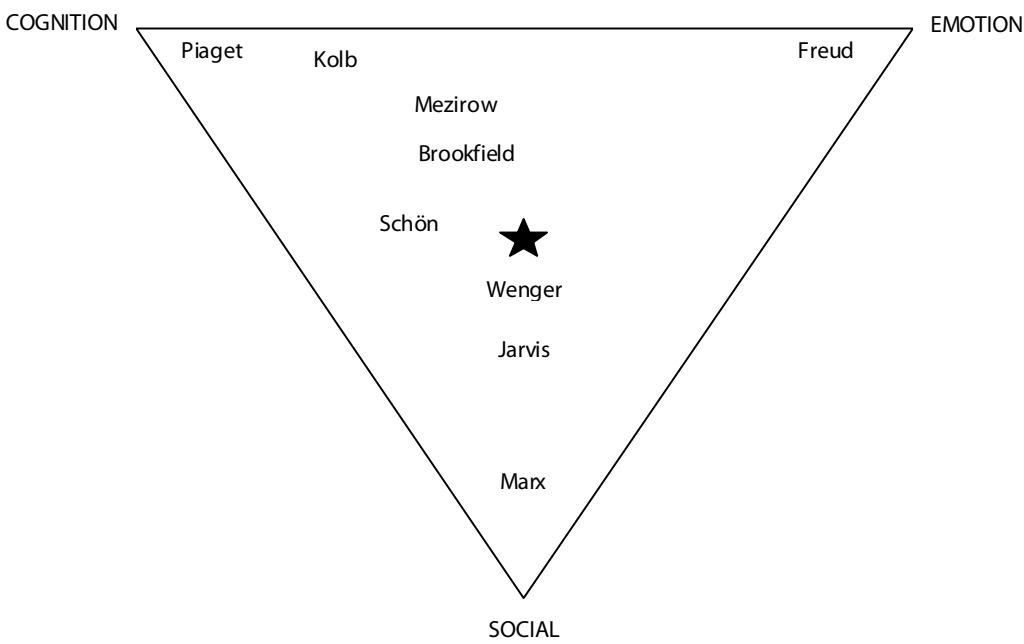


Going back to first principles is useful to researchers hoping to develop better understandings of work, industrial and labour relations and the learning process. Illeris (2002) begins his discussion of the tensions field of adult learning theory with a focus on cognition rooted in the foundational works of Piaget (cf. Gruber and Vonèche, 1977). From here, as across each dimension of the tension field, Illeris then assesses contemporary research that, either implicitly or explicitly, expresses or develops upon the perspectives of the foundational author. Indeed, individual cognition is one of the most persistent, orienting principles of mainstream learning theory as well as conventional thought in both schools and workplaces alike. There is little reason to believe that Piaget's core theoretical contributions are not as valid today as they were when they shook the world of psychology in the early $20^{\text {th }}$ century. His model of cognitive schemes and the patterns through which they undergo change are instructive. However, the portrait of change established by Piagetian thought - in isolation - can be characterized as conservative. Consider, for example, the key Piagetian principles of 'equilibration, 'adaptation', and 'assimilation' through which an individual strives to maintain a steady state in his or her interactions with the surrounding world. Here we see a description of individual change but social stasis. Countering this somewhat is the Piagetian concept of 'transcendent learning': the adaptation of the environment to meet an individual's established cognitive schemes. However, this concept was less clearly addressed by Piaget or those rooted in this tradition, despite the fact that Piaget partially anticipated related issues in his later years (cf. Piaget \& Garcia, 1989). Nevertheless, the degree to which core Piagetian principles of human learning are expressed in adult learning theory today remains striking.

Illeris (2002) also understands that learning is libidinal or emotionally lad$e n$, that meaningful learning analysis must combine observations from cognitive psychology (i.e. dealing with learning content such as skill and knowledge), on the one hand, and observations from the psychology of personality (i.e. dealing with motivations, affect, attitudes, and desires) on the other. Just as cognition matters, so too does emotional development shape adult learning. As he did in his discussion of cognition, Illeris returns to first principles with the work of Freud. For Freud and Freudians in the field of psychology, development is related to the theoretical discovery of the unconscious and the fundamental and innate expression of the pleasure and reality principles, which results in a gradual expansion of the powerful, symbolic framework that eventually stabilizes as internal images, fantasy, desires, fears, defence mechanisms and the orienting motivations that establish what we think of as personality. As Illeris notes, 'cognitive learning is always affectively 'obsessed': there are always emotional tones or imprints attached to the knowledge being developed... These provide the psychological energy for learning' (pp. 73-74). For researchers hoping to meaningfully engage with, for example, instances of what have been called 'non-learning,' 'mis-learning,' and any other otherwise unintentional outcomes of work, training or schooling experiences (see Illeris, 2002, for a summary), assessments of the emotional dimensions of learning are crucial. What remains to be considered according to Illeris's (2002) tension field 
model, however, is the question of social context, its character, and its role in the learning process.

In terms of this social dimension, for Illeris (2002) the key figure here is Marx whose theory of societal change is said to be foundational. Marx and Marxists' detailed investigations of forces and relations of production are central. Drawing on sociologist Oskar Negt however, Illeris focuses on relations of experience and communication. Learning is deeply shaped by social interaction, analysed by Negt with reference to conflicting public spheres, defined as the many overlapping systems of communication through which adults become informed and develop according to distinctive social standpoints. It is thus composed of a system of domination and power that produces distortions of experience through systematic patterns of distribution of communicative resources. In this context, the eviscerated experience shaping working-class community discussed earlier is an example of the decline of working-class public spheres (cf. Negt and Kluge 1993): A sphere constituted not simply by community and neighbourhoods but by workplaces as well.

Useful, indeed path-breaking, as Illeris's framework is, it is not however perfect. The tension field model provides a substantive attempt at integrating the key dimensions of human developmental capacities, yet there remains the issue of articulation. Is there a conceptual element missing from Illeris's work that would help us to further understand how the cognitive, emotional, and social dimensions relate to each other and that in turn, can coherently bring them under the same unit of analysis? For this we turn to what is known as socio-cultural learning analysis which continues to gain popularity amongst a range of scholars interested in how learning actually gets done in and in relation to work. A key sub-school of socio-cultural theory is Marxist Cultural Historical Activity Theory (CHAT). Its most important contribution for our purposes here is the concept of 'mediation'.

The concept of mediation can best be introduced by retracing the steps of one of the leading, contemporary voices in the tradition, Yrjö Engeström (1987). Building on the seminal work of the Russian psychologist Lev Vygotsky (1987), Engeström's goal was to understand the range of symbolic, social and material mediations of individual and collective human practice as a learning process. Mediation refers to an important and often ignored process through which people (individually and collectively) interact with the world. This principle says that a person or subject always, without exception, interacts with the world and achieves outcomes through symbolic and/or material tools or artifacts. These artifacts can run the gamut of possibilities. An artifact could refer to the types of cognitive schemata described in the cognitive traditions, it could refer to the type of libidinal structures outlined in the psychodynamic tradition, or it could refer to the types of material or institutional structures, rules, norms and conventions as understood in the sociological tradition. Moreover, the concept of artifact mediation indicates a strong orientation to temporal dimensions of learning and development, i.e. artifacts each have a history of production, affording some forms of social practice and inhibiting others. 
At the turn of the $20^{\text {th }}$ century in the exuberant years of pre-Stalinist Russia, Vygotsky's goal was nothing less than a complete reorganization of the psychology of learning and development, with an emphasis on a dynamic (or rather dialectical) theory of culture, materialism, and social history. In contrast to the natural science roots of Piagetian and Freudian traditions (these theorists were initially trained in biology and physiology respectively), Vygotsky's concept of mediation veered toward the sociological. Vygotsky's claim was based on the argument that social participation was primary to the development of higher order mental functions of cognition, emotion, motivation, and self-directed behaviour. For Vygotsky, the concepts of 'turning' or 'interiorisation' defined the process through which external social relations - in fact, whole socio-historical systems in a constant process of change - are translated into the internal mental functions, outcomes and embodied states that we associate with common-sense notions of knowledge, skill and learning. Vygotsky's approach, deeply influenced by the basic Marxist observation that 'social being' determines 'consciousness' far more often than the other way around, centred on this principle of symbolic and material mediation. As indicated in Figure 2, Vygotsky first challenged the notion of unmediated action (plate 1 of Figure 2) to claim all social action is mediated (plate 2). What eventually emerged was the concept of learning as a developmental 'activity system' (Leont'ev 1978). This activity system analysis incorporates both individual responses as well as the organization of work, labour relations and community more broadly, in order to account for learning in all its forms. These include both organized and informal, everyday learning, with the final item (plate 3 of Figure 2) generating an account of multiple, mediational processes, some directly connected to the purpose/goal/object of activity, but many others not.

FIGURE 2: Progression from Non-Socio-cultural Approaches to Learning to Activity Theory Analysis

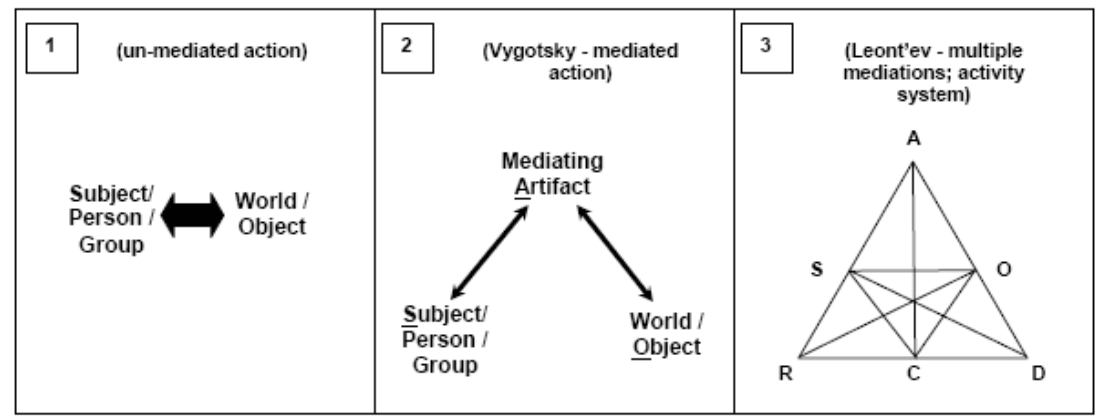

Legend: (image 3) $\mathrm{S}=$ Subject; $\mathrm{A}=$ Mediating Artifact; $\mathrm{O}=$ World $/$ Object; $\mathrm{R}=$ System Rules; $\mathrm{C}=$ Community Conventions; $\mathrm{D}=$ Division of Labour 
In the remaining figures we apply this activity system analysis, at times looking at the content of activity systems in detail and at other times examining trajectories of change in activity systems over time. In terms of the latter, we reference Vygotsky's concept of the 'Zone of Proximal Development' (ZPD). The zone of proximal development marks the developmental process. Generally speaking, it refers to the gap between a learner's independent problemsolving and the developmental capacity realized through social interaction and collaborative problem-solving, with development being mediated though a process in which artifacts are interiorised as psychological tools.

My argument - the argument of CHAT analysis - is that the contradictory way that artifacts of all kinds mediate our interaction with the world around us is the glue that holds together the different dimensions of learning identified by Illeris within his tension field analysis. In other words, what is common across the cognitive, emotional, social (material and symbolic) dimensions of developmental processes is that each can be understood as instances of mediation. Whether it is the way that people's engagement in work is mediated by work skill (cognitive), by a need for recognition, a fear of authority or even a passionate commitment to social justice (emotional), or by socially-established workplace policies, collective agreements and so on, these myriad instances of mediated practice provide the substance of an account for the systems of activity that define current and future development. Indeed, this broader notion of learning provokes a particular interest; one less concerned with organized sites of training and education and more concerned with how both organized and everyday learning form complex spheres of overlapping activity.

\section{Mediations, Activity Systems and Contradictions within Working-Class Learning}

In moving forward with answers to the question of what work teaches the working-class, I want to focus on the paid workplace as one amongst an ensemble of social spheres which interact across time to expose how mechanisms of working-class learning operate. The 'activity system' is the unit of analysis of CHAT. It is allows us to identify systematically the diverse mediation processes across a range of social spheres. However, before going further it is important to note that a vital contribution to this analysis is the application of the concept of 'habitus' developed in the work of sociologist Pierre Bourdieu. This concept is a central component of his sociology of position and disposition, a politicized science of the schemata of perception and appreciation. The habitus is defined as,

... [a] generative and unifying principle which retranslates the intrinsic and the relational characteristics of a position into a unitary lifestyle, that is, a unitary set of choices of persons, goods, practices. Like the positions of which they are a product, habitus are differentiated, but they are also differentiating. Being distinct and distinguished, they are also distinction operators, implementing different principles of differentiation or using differently the common principles of differentiation. (Bourdieu, 1998: 8) 
The habitus thus represents a particularly important artifact for articulating the effects of social difference and social consciousness. It allows us to conceptualize Vygotsky's original concerns about the relationship between thought and the 'motivating sphere of consciousness, a sphere that includes our inclinations and needs, our interests and impulses, and our affect and emotion [which] stands behind thought' (Vygotsky 1987: 282). Indeed, in Sawchuk (2003) I provide an extended argument concerning patterned forms of participation rooted in the unique cultural and material contexts of workingclass standpoints as evidence of a working-class 'learning' habitus (cf. Nash 2005's notion of 'cognitive habitus').

Seen in relation to a system of activity, however, the habitus like all artifacts produces and expresses contradictions in the course of mediation. At the centre of this attention to contradictions are the relations of legitimate and illegitimate social standpoints. Legitimacy, in this sense, is a socio-political notion and a function of communities of interest ratified through their linkages with one or more legitimate societal institutions.

To elaborate on this point briefly, at the heart of this definition of the relation between legitimacy/illegitimacy is, from a Marxist perspective, the primary contradiction of the bulk of (work and non-work based) activity systems under capitalism, i.e. the contradiction between use and exchange value within the commodity form. Indeed, Marx's labour theory of value and his opening discussion of the commodity form in Capital Volume 1(1867/1986) have a relatively simple message understood by Marxists and non-Marxists alike. Despite regular instances of cooperation, work is just as regularly the site of conflict as the needs of capitalist economic competition, labour relations and technological change necessarily come into contradiction with the immediate satisfaction of human needs. These may be the need for health and safety, the need for meaningful experiences or the need for humane interrelations with others (see Sawchuk 2006a). Translated, this represents the contradiction between 'exchange value production' and 'use-value production' respectively.

Importantly, this political economic philosophy is directly expressed by the CHAT approach to learning. Thus there is a unity of opposites between usevalue orientations (i.e. learning/activity governed in the last instance by the production of 'use value') and exchange value orientations (learning/activity involving use-value but governed in the last instance by the production of 'exchange values'). This unity of opposites represents the parallel, mutually constituting but opposing dimensions of mediation that define human development. However, under capitalism, systems of activity governed by use-value production are regularly deemed, at best, irritating externalities of production (e.g. soldiering, gold-bricking, intransigence) and at worst illegitimate social ills (e.g. sabotage, militant trade unionism, political organizing and social unrest): they undermine efficiency and the fluidity of market relations. That is, use-values such as comfort, social justice, solidarity, and even democracy - to the degree that they truly govern (as opposed to merely accompanying) decision-making within activity systems - are likely to be understood as problems within all but the most expansive, 'social economy' approaches to economic 
activity. Leaving aside the contradictory and uneven achievements of empowerment, quality programs or high performance work systems (cf. Edwards and Collinson 2002; Frenkel 2003), these use-value orientations are regularly either treated as irrelevant or else directly, and under capitalism necessarily, attacked by management. None of this is to say, however, that under capitalism these forms of use-value production are unimportant, only simply that they must be governed by the ongoing production of exchange-values.

Socio-cultural theories such as CHAT recognize that these contradictory processes of value production mediate human learning in relation to the experience of work. For CHAT analysis, learning is driven by this core contradiction along with related peripheral contradictions (Engeström 1987; Sawchuk $2003,2006 a, b)$. Thus learning occurs as these contradictions are either positively resolved producing 'expansive learning' in Engeström's terminology or they are fomented to produce 'contracted learning'.

With these concepts and the previous discussion of adult learning theory in hand, for the remainder of the article we turn our attention to some brief illustrations that explore the notion of 'class consciousness' as a learning process: In many ways the central learning outcome that defines what it is that work teaches the working-class.

\section{Learning to Be Dominated}

Epochal activity, that is activity confined to its own historical epoch, is defined under capitalism as activity which has as its broader organizing structure (or 'motive' in the language of CHAT) the production of exchange-values and the commodification process broadly conceived. This may be the production of goods or services for one's employer. It can also mean, for example, the obtaining of an educational credential for the purposes of exchange on a labour market. And, it might also mean learning applied to the gaining of a promotion, and so on: in generalized form, the generation of human capital for the purposes of accumulating exchange-value. In all cases, it is activity governed by the logic of capitalist exchange in some form of (internal or external) market relationship. In terms of learning/activity systems perhaps the most typical expression of this in my research interviews were statements such as the following: 'I engage in education and training to learn something else and to make myself more marketable' (Clerical Worker). Many workers express this orientation. It is pragmatic, legitimate and even celebrated under capitalism, as a type of career development. We can note, however, how this simple orientation is linked to broad forms of participation which overlap across a number of social spheres (e.g. schooling, work-based training and labour market participation) all in a way governed by exchange-value production.

To better understand activity system changes, below I draw on a conventional CHAT diagram. These diagrams are related to the graphic representation used in analysis by Engeström in an effort to show how a subject's practices are mediated by a range of artifacts in a form of dialectical change. My analytic method here is to map specific strips of interview data onto the model 
to expose the internal relationships. Such diagrams as I use them in this article are necessarily heuristic. Given space limitations, the diagrams summarize rather than fully demonstrate analysis. Nevertheless, Figure 3 attempts to capture the tenor of the type of learning/activity system addressed by interviewees such as the clerical worker quoted above. The modifications to the Engeströmian triangle model include an attempt to represent core contradictions with the addition of the use-value and exchange-value dashed line, which indicates the overall governance or orientation of the activity system over time.

The use of the dashed line is far from a perfect way to represent the mutual constitution of use- and exchange value dialectically. However, it is in the end the overall legitimate/illegitimate governance of activity systems that is at issue, and hence we can still note that, for example, the key concepts of the legitimate learning/activity system (school) straddle this dashed line. This is because, arguably, learning does legitimately serve both the direct needs of individuals and at the same time actively incorporates those same individuals into a form of (credential/labour market) exchange: that is, education can and does serve the needs of humans directly as valuable 'in itself' at the same time it serves the capitalist economy. Further, however, we can note that legitimate learning/activity systems identified flowing forward in time (left to right) into adulthood come to be positioned below the dashed line, firmly governed by exchange-value orientation and commodification. Work-based activity systems including training programs and development inherent within the labour process itself are a subset of larger societal legitimate knowledge activity systems and thus occupy a position embedded in them, again largely governed by exchange value production.

FIGURE 3: Class Domination in Knowledge Activity Systems \& Work Development

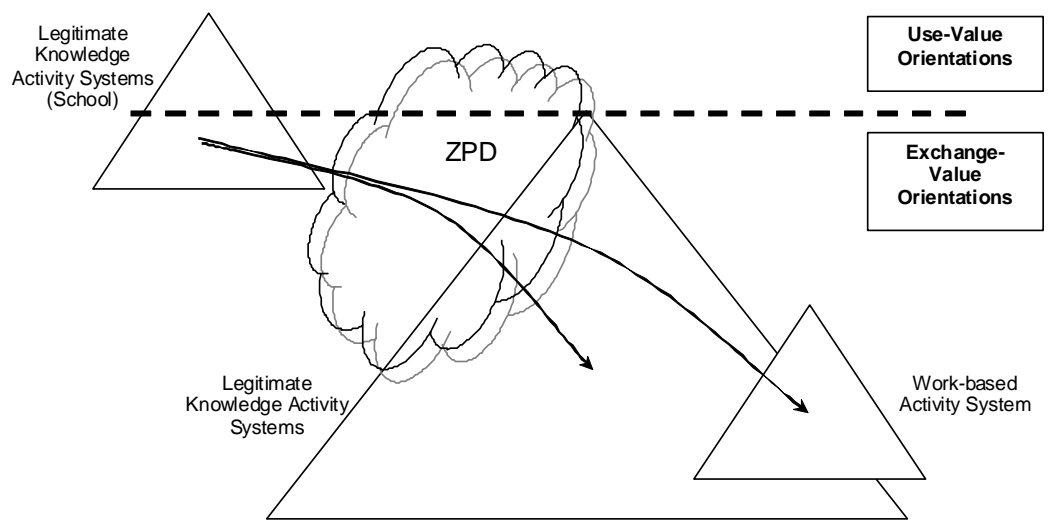

Each of the triangles in Figure 3 represents a specific system of mediation and activity that defines the learning process at any one point in time. A slightly more detailed examination of the content of dominating forms of workingclass learning/activity is shown in Figure 4. 
FIGURE 4: Unresolved Contradictions and Weak Mediations in WorkBased Activity Systems from a Working-Class Standpoint

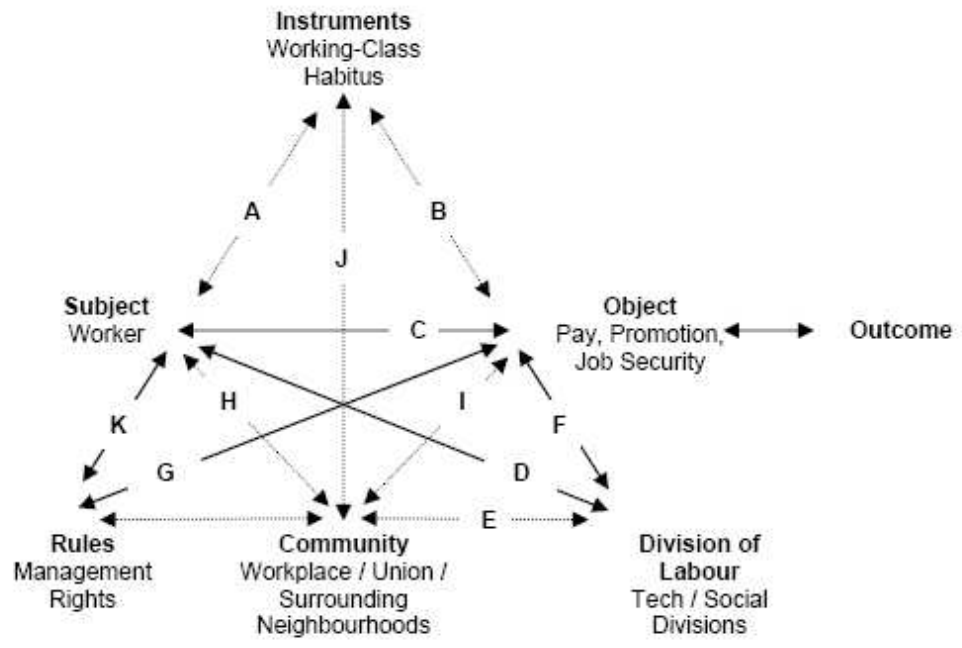

Figure 4 typifies dominated learning with its unresolved contradictions and weak mediations (represented by dotted lines). For example, workers in my research whose learning seemed to best exemplify this dominated learning/ activity experienced a host of weak mediations in relation to both the workingclass habitus and community. The capitalist labour process was the core mediating artifact in terms of work rules/company policy (the mediation triangle formed by lines K-G-C) and specific divisions of labour (the mediation triangle formed by lines D-F-C). That is, interviewees actively described how their pursuit of pay, promotion and/or job security was predominantly mediated by the management rules and the division of labour. In either case, the subject does not produce work outcomes directly but rather through the activation or use of the specific artifacts which define organizational rules and divisions of labour. Likewise, low levels of personal engagement (i.e. all the weak mediations in relation to the habitus and working-class community) restricted capacity to augment work/life systems by building on the learning developmentally. This is reflected in Figure 4 by the subject lacking strong mediational connections to either culturally or materially stable communities (unionized or otherwise) or their own working-class habitus. These are depicted as weak mediations (e.g. mediation triangles formed by lines A-B-C and H-I-C) which in general can be understood as mismatches between subject, conditions, artifacts and object. These patterns of mediation represent a basic activity analysis of the eviscerated conditions of working-class communities discussed earlier where neither positive expressions of working-class identity nor functioning working-class communities are well integrated into people's learning lives. Importantly, these mediational patterns throw forth contradictions (e.g. peo- 
ple cannot produce the desired outcomes effectively, they feel their pay is inadequate, they experience anomie, disenchantment or alienation, etc.). It is the subsequent and ongoing responses to these contradictions that produce alternative patterns of mediation, mostly via individual changes (e.g. increased effort, manic credential-seeking, deeper participation in management programs, or intransigence, tacit withdrawal and possibly exit) which form the basis for an analysis of learning within this process of 'learning to be dominated. All of this emerges not from one line of interview transcription from a clerical worker, but rather from an extended analysis of the learning life history transcripts as a whole. In our interviews with a manufacturing worker seeking promotion to Quality Inspector, with janitors seeking to respond to threats of contracting out, with home-workers in the garment industry struggling to meet production quotas, and so on (Livingstone and Sawchuk 2004) - worker's descriptions detail the governing processes of mediation including the specific artifacts, conditions, goals and overall structure of activity in their work/life, ultimately providing an explanation of why certain patterns of learning emerge and others do not.

\section{Learning to Resist}

CHAT as elaborated by Vygotsky's friend and collaborator A. N. Leontev (1978) defines goal-directed actions as conscious whereas both operations (related to local conditions of practice) and the broader motive of activity (related to institutional, social and political economic contexts) are typically beyond the self-conscious attention of people as they learn. This conceptualization of three levels of activity is important for understanding working-class learning.

In Chapter 2 of Engeström (1987) we find a treatment of different practices of memory which is related to this notion of unconscious versus conscious dimensions of activity. Engeström draws on research that distinguishes voluntary as opposed to involuntary memory through the structural location of the specific purpose/object of memory within the structure of activity. Building on this type of thinking, we can examine how the learning outcomes of activity change according to the shifting structural position of the working-class habitus in the activity system. Through this type of analysis we can better see how engagement in particular activity systems (e.g. militant trade unionism, political organizing or a functional working-class community) produce changes in, for example, class consciousness. Participation in the trade union activity system, for the man speaking in the excerpt below, established the possibility for the conscious articulation of his class position vis-à-vis the structural position of the habitus in activity. In effect, this structural shift in activity accounts for the change through which the background dimensions of class life move to the foreground of consciousness, and hence come to more strongly mediate learning.

Education? I don't have any, I don't believe in it. I left school when I was 15. Never stayed on further than I had to.... My real learning came when I joined the Miner's strike. You learned what the state apparatus 
is, keeping people in order, protecting the issues. That was my education... [In fact] the trade union's role as I see it is to highlight what knowledge we actually do have and how we attain it. How we actually do learn things, and I'll give you an example a quick example. [Workers I know] learned about health and safety the hard way. They learned about workers' compensation the hard way. Only through their experience. They never went to any course - they learnt it when the employer screwed them and then they had the time to sit down and say, 'Why'd they do that to me after all I've given them.' And that's the best, unfortunately it's the hardest as well, the best experience a worker can get because it cuts through all the nonsense because it hits you directly, it gives you time to think and to read and ask questions and start understanding what it's all about.

FIGURE 5: An Example of 'Resistance' Knowledge Activity Development

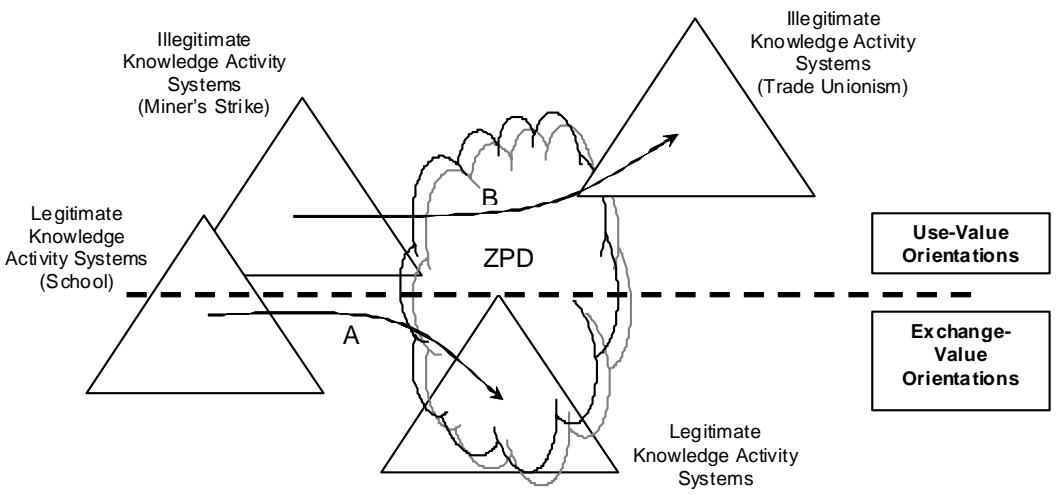

Graphically represented, we see this system of learning/activity in Figure 5. This union activist outlines the role of an existing, culturally and materially stable community of workers as well as the organizational form offered by the union which produces a shared object of inquiry based on the assumption of conflictual class relations. The content of the habitus changes: it becomes more articulate and developed as a positive expression of identity. This workingclass habitus also comes to take on an increasingly important role as a mediating artifact in ongoing activity. When structurally located within the activity system as a prominent mediating cultural artifact (Figure 6) it accounts for politicized 'class reflexes', the fabric of the best traditions of working-class culture. In the instances when the working-class habitus is structurally located within the activity system as a purpose/object (i.e. practices of building a politicized, self-awareness) we see emerging something that we might call critical class consciousness.

As I have said, accounts of strong/weak mediation are derived from the interview transcripts as a whole. In following the transcript further, for example, we can see how the general activity system of Figure 6 helps explain partic- 
ular responses to labour relations conflict, for example when this same man goes on to describe a specific contradiction in the his manufacturing facility:

In our collective agreement we've got a training rate of 25 cents an hour... but basically you're selling your knowledge for nothing. We're giving away our knowledge for nothing because if you look at it - if the worker doesn't train the worker then who is going to train them? The knowledge needed to do any type of job... if you tried to bring in consultants it would cost thousands... And the company says, we should be grateful for the opportunity, and at times weve even had to grieve for the 25 cents per hour!

\section{FIGURE 6: Re-Instrumentalising Knowledge Activity and the Emergent Horizon of Working-Class Struggle}

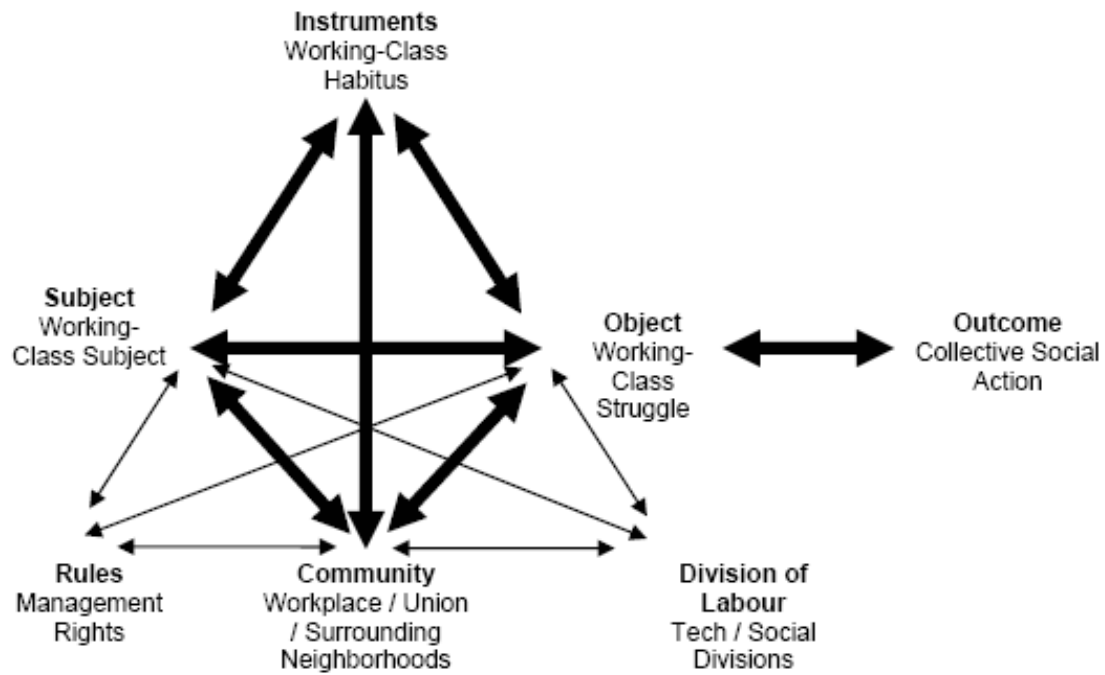

What explains the emergent perspective (a more militant standpoint, though one that is clearly not entirely isolated from the realm of exchange-value) and subsequent action (the union local's revised training rate bargaining proposal the following round of negotiations; see Livingstone and Sawchuk 2004) was the basic pattern of activity represented in Figure 6 where an increasingly functional working-class community (the union local) and the collective habitus (working-class cultural dispositions) mediated an attempt to resolve a systemic contradiction. A specific artifact - the training-rate policy - mediated specific forms of activity expressing a systemic contradiction, which combined with mediation by a functioning working-class community formation led to specific actions, learning and development of individual/collective class habitus. My point here is that, in the minutiae of this small example are the possibility of a broader appreciation of the conditions through which resistant mil- 
itancy actually emerges, and how this emergence is reflected through mediated practices operating across the cognitive, emotional, social (material and symbolic) dimensions.

\section{Conclusion}

I claim that analysis of the mechanisms of human development can make an important contribution to a more coherent understanding of the ongoing processes of reproduction and development of economic and labour relations. In this article I have explored a particular way to think about social class and the learning process. I argued for the significance of these concerns early on when I briefly outlined how these capacities, in the context of the decline of working-class community, are challenged under late capitalism. A brief review of learning theory then led to my claim that an appreciation of the concept of 'mediation' may be central to understanding the fullness of human learning generally, and working-class learning specifically aided by the application of Bourdieu's concept of habitus. Following this, I presented a basic two-part typology of different forms of learning that define working-class development across work and community life.

The analysis suggests, if nothing else, the political significance to be found in the mundane, hidden and taken-for-granted world of working people's everyday lives. The working-class can be seen to learn a great deal from work on an ongoing basis particularly when the workplace is understood amidst an ensemble of related social spheres. What and how the working-class learns, however, can vary radically depending on different patterns of mediation. What is clear here is that learning is a complex process; a complexity that is obscured by the many 'proxy' analyses of learning, knowledge and skill that characterize so much literature today (Warhurst and Thompson, 2006).

In terms of how different outcomes are achieved, analysis revolves around the way that the working-class habitus undergoes a double transformation in terms of content as well as structural position within learning/activity systems. The working-class habitus tends to mediate practice at the operational level of activity under conditions of domination, while under the conditions of resistance we see what Engeström (e.g. 2000) refers to as a significant re-instrumentalisation of activity where the habitus becomes a central tool and, at points, a purpose/object of activity. 


\section{References}

Bourdieu, P. (1998) Acts of Resistance: Against the Tyranny of the Market, The New Press, New York.

Charlesworth, S. (2000) A Phenomenology of Working Class Experience, Cambridge University Press, New York.

Edwards, P. and Collinson, M. (2002) 'Empowerment and managerial labor strategies: Pragmatism regained', Work and Occupations, 29(3), pp. 272-299.

Ehrenreich, B. (2002) Nickel and Dimed: On (Not) Getting By in America, Metropolitan, New York.

Engeström, Y. (1987) Learning by Expanding: An Activity-Theoretical Approach to Developmental Research, Orienta-Konsultit, Helsinki.

Engeström, Y. (2000) 'From individual action to collective activity and back: Developmental work research as an interventionist methodology' in P. Luff, J. Hindmarsh and C. Heath (eds.), Workplace Studies: Recovering Work Practice and Informing System Design, Cambridge University Press, New York, pp. 150-166.

Fenwick, T. and Farrell, L. (eds.) (in press) Educating the global workforce: Knowledge, knowledge work and knowledge workers, Kogan Page, New York.

Fenwick, T., Nesbit, T. and Spencer, B. (eds.) (2006) Contexts of Adult Education: Canadian Perspectives, Thompson Educational Press, Toronto.

Foley, G. (1999) Learning in Social Action: A Contribution to Understanding Informal Education, Zed Books, London.

Forrester, V. (1998) L’horreur économique, Fayard, Paris.

Frenkel, S. (2003) 'The embedded character of workplace relations', Work and Occupations, 30(2), pp. 135-153.

Gruber, H. and Vonèche, J. (eds.) (1977) The Essential Piaget, Basic Books, New York.

Illeris, K. (2002) The Three Dimensions of Learning: Contemporary Learning Theory in the Tension Field between the Cognitive, the Emotional, and the Social, Roskilde University Press, Frederiksberg.

Leont'ev, A.N. (1978) Activity, Consciousness, and Personality, Prentice Hall, Englewood Cliffs.

Livingstone, D.W. and Sawchuk, P. H. (2004) Hidden Knowledge: Organized Labour in the Information Age, Garamond Press, Toronto.

Maddison, A. (1982) Phases of Capitalist Development, Oxford University Press, London.

Marx, K. (1867/1986) Capital (Volume I), Penguin, New York.

Nash, R. (2005) 'The cognitive habitus: Its place in a realist account of inequality/ difference', British Journal of Sociology in Education, 26(5), pp. 599-612.

Negt, O. and Kluge, A. (1993) Public Sphere and Experience: Toward an Analysis of the Bourgeois and Proletarian Public Sphere, University of Minnesota Press, Minneapolis.

Piaget, J., \& Garcia, R. (1989) Psychogenesis and the History of Science, Columbia University Press, New York. 
Putnam, R. (2000) Bowling Alone: The Collapse and Revival of American Community, Simon \& Schuster, New York.

Sawchuk, P. H. (2003) Adult Learning and Technology in Working-Class Life, Cambridge University Press, New York.

Sawchuk, Peter H. (2006a) "Use-value" and the re-thinking of skills, learning and the labour process', Journal of Industrial Relations, 48(5), pp. 589-613.

Sawchuk, P. (2006b) 'Activity and power: Everyday life and development of working-class groups', in P. Sawchuk, N. Duarte and M. Elhammoumi (eds.), Critical Perspectives on Activity: Explorations Across Education, Work and the Everyday, Cambridge University Press, New York, pp. 238-267.

Staff (2006) 'The Forgotten Underclass', The Economist, October 28 ${ }^{\text {th }}$, pp. 65-66.

Swift, J. (1995) Wheel of Fortune: Work and Life in the Age of Fall Expectations, Between the Lines, Toronto.

Vygotsky, L. (1987) The Collected Works of L. S. Vygotsky (Volume 1): Problems of General Psychology, Plenum Press, New York.

Warhurst, C. and Thompson, P. (2006) 'Mapping knowledge in work: Proxies or practices?', Work, Employment and Society, 20(4), pp. 787-800. 